\title{
Pachakuti e a história da modernidade nos mares do Sul
}

SILVA, Filipe Gervásio Pinto da ${ }^{1}$

\section{RESUMO}

O texto trata da construção da modernidade colonialidade, a partir de um diálogo entre o Materialismo Histórico-Dialético (LUKÁCS, 2010; MARX, 2007; 2013) com as Epistemologias do Sul (SANTOS, 2010A; QUIJANO, 2005; MIGNOLO, 2011). Três são os pontos centrais da reflexão: o rompimento do silêncio absoluto que envolve a importância da América Latina na construção da modernidade capitalista; a vinculação metabólica entre modernidade e colonialidade, uma vez que a o estágio das forças produtivas e da consolidação do eurocentrismo como núcleo duro da vida intelectual mundial possuem uma vinculação estreita com o regime de acumulação primitiva, colonização e racialização dos territórios latino-americanos e, por fim; a introdução de uma premissa ontológica materialista ao debate epistemológico do Sul Global, é o de que a colonização foi o momento matricial da imposição planetária da Forma-Mercadoria (MARX, 2013).

\section{América Latina. Modernidade/Colonialidade. Ontologia.}

\section{Pachakuti and the history of the modernity beyond the Southern seas}

The text deals with the construction of modernity-coloniality, starting from a dialogue between Historical-Dialectical Materialism (LUKÁCS, 2010; MARX, 2007; 2013) and Southern Epistemologies (SANTOS, 2010A; QUIJANO, 2005; MIGNOLO, 2011). Three are the central points of reflection: the breaking of the absolute silence that surrounds the importance of Latin America in the construction of capitalist modernity; the metabolic linkage between modernity and coloniality- since the stage of the productive forces and the consolidation of Eurocentrism as the core of the intellectual world life have a close connection with the regime of primitive accumulation, colonization and racialization of the Latin American territories and, finally, the introduction from a materialist ontological premise to the epistemological debate of the Global South, is that colonization was the matrix point of the planetary imposition of the FormMerchandise (MARX, 2013).

Latin America. Modernity/Coloniality. Ontology.

\footnotetext{
${ }^{1}$ Mestre em Educação Contemporânea. Professor da Área de Fundamentos Sócio-históricos, da Unidade Acadêmica de Educação do Campo, da Universidade Federal de Campina GrandeCentro de Desenvolvimento Sustentável do Semiárido/UFCG-CDSA, doutorando do Programa de Pós-graduação em Educação da UFPE, Email: filipe.gps@hotmail.com
} 


\section{INTRODUÇÃO}

A palavra Pachakuti circula o universo histórico e simbólico de diversas cosmologias indígenas presentes na América Latina, tendo significados variados mas que podem ser agrupados em torno de um núcleo fundamental que aponta para "mudança ou alteração da terra", "reformador da terra", ou até mesmo, como prefere Mignolo (2005); "mudança brusca" ocasionada pela invasão dos territórios Abya Yala ${ }^{2}$. Seja como for, Pachakuti é uma maneira não hegemônica de narrar o nascedouro daquilo que o mundo europeu- em sua fração triunfante e hegemônica sobre as outras Europas- se acostumou a chamar de modernidade.

Pachakuti aqui tem ainda um sentido de nomear uma tentativa teórica de construir um relativo abandono às narrativas triunfantes produzidas na e pela modernidade/colonialidade, entendida como expressão cujas faces pertencem à mesma moeda, como nos lembra Quijano (2005). Abandono relativo porque, por um lado se desprende da geopolítica dos interesses econômicos e civilizacionais que tornaram possível a colonização e 0 auto olhar contemplativo da modernidade capitalista sobre si; por outro, porque $\mathrm{o}$ abandono dos povos colonizadores e de suas referências e interesses históricos nos impossibilita uma compreensão ampla do que ocorreu e ocorre na própria América Latina. Não é possível compreender o laço civilizatório e o padrão mundial de poder (QUIJANO, 2005) criado através da colonização, se uma das pontas deixa de ser interpelada como parte deste mesmo laço ou como parte do quase "nó cego".

A colonização nos obrigou, neste sentido, a estarmos perpetuamente relacionados, de modo que a compreensão do conjunto de determinações históricas do alvorecer da modernidade e de seu aprofundamento não nos poderá dispensar de compreensão profunda destes mundos antes descolados e que depois passaram a se determinar mutuamente, ainda que de maneira assimétrica.

Se quisermos ainda uma figura de pensamento elucidativa sobre a questão, recordemos então o "Manifesto da Decolonialidade", escrito por Mignolo (2007), cujo subtítulo apresenta a ideia de "desprendimento e abertura" como atitudes simultâneas de compreensão e intervenção na situação colonial. No título do manifesto da decolonialidade está também presenta a ideia de "desobediência epistêmica", que parece ser o traço mais fundamental de toda a literatura decolonial e dos movimentos sociais e políticos que a ensejam, ainda que em alguns momentos apareça relacionada à desobediência civil.

\footnotetext{
2 Nomenclatura utilizada por diversos povos indígenas que significa afirmação das identidades nativas nos territórios colonizados. Abya Yala significa "terra em plena madureza" ou "terra de sangue vital".
} 
Não é parte das motivações deste texto, ainda que nos pareça importante, questionar até que ponto os epistemólogos do Sul Global exercitam a abertura e o desprendimento em suas próprias teorizações. De igual modo, não há também a pretensão de construir uma crítica à ideia de desobediência epistêmica, senão alimentar as possibilidades desta forma de enfrentamento com um solo comum e indispensável, que é o da compreensão da importância da dimensão ontológica para a elucidação do ser social (MARX, 2007; LUCKÁCS, 2010; LESSA E TONNET, 2011) e consequentemente da construção histórica da América Latina. Esta dimensão ontológica do ser social reporta à dimensão do trabalho e da reprodução histórica da vida material, como base para a reprodução social em suas janelas culturais, políticas, intersubjetivas e epistemológicas.

O que está de fundo a esta compreensão é que as já consagradas Epistemologias do $\mathrm{Sul}^{3}$, que apresentam a visão das ruínas da modernidade, como projeto civilizacional, ainda que não explicitem, não deixam de prescindir de uma ontologia. Esta ontologia não referida explicitamente quase sempre está referida ao Discurso, dada a influência de autores pós-estruturalistas e pós-colonialistas que integram o heterogêneo conteúdo das Epistemologias do Sul. A não saturação desta dimensão ontológica nos lega uma compreensão insuficiente ou distorcida da América Latina em seu sentido mais profundo que é o da sedimentação histórica deste território no mundo capitalista através de sua subordinada e dependente inserção mundial.

Lançamos mão da abordagem materialista histórico-dialética em diálogo com noções-chave do Pensamento Decolonial e da Sociologia das Ausências e a Sociologia das Emergências, que ajudam a compor um movimento teórico geral que estamos designando por Epistemologias do Sul' ${ }^{4}$ Estas abordagens ajudam a contar a história da colonização e da colonialidade, respectivamente como marcos fundacionais e contemporâneos da atual idade do capitalismo e da sociedade moderna.

Os pontos de partida são três. O primeiro diz respeito ao silêncio absoluto que envolve a importância da América Latina na construção da modernidade capitalista, como se a modernidade e a chamada "fase adulta da produção", o capitalismo fossem o resultado de uma evolução europeia sem nenhuma relação com o saque e a desumanização coloniais. O curso da argumentação aqui empregada evidencia justamente o oposto.

\footnotetext{
${ }^{3}$ Conjunto heterogêneo de teorias e esquemas analíticos que adotam o Sul Global como metáfora do sofrimento humano e como referência epistemológica para a explicação e transgressão da modernidade (SANTOS, 2010a). Aqui a expressão Epistemologias do Sul será utiliza em diversos momentos para sinalizar o conjunto de referências teóricas aludido acima.

4 Haverá sempre uma arbitrariedade em categorizar as heranças e agrupamentos teóricos, ainda mais em um conjunto tão diversificado de perspectivas teóricas que se propõem a teorizar a América Latina. Desta forma, fica para outro texto o propósito de analisar com mais profundidade as diferenças entre pensamento Decolonial, Epistemologias do Sul, Estudos Póscoloniais, Estudos da Subalternidade, dentre outros.
} 
O segundo ponto de partida é o de que, em decorrência do primeiro, não existe modernidade sem colonialidade, uma vez que a o estágio das forças produtivas e da consolidação do eurocentrismo como núcleo duro da vida intelectual mundial possuem uma relação metabólica com o regime de acumulação primitiva, colonização e racialização dos territórios latinoamericanos. Também a criação de um arcabouço simbólico, estético e epistemológico de consagração do Eurocentrismo dependeu decisivamente da exploração e da dominação colonial.

O terceiro ponto de partida, que tende a sintetizar os dois primeiros e introduzir uma premissa ontológica materialista ao debate epistemológico do Sul Global, é o de que a colonização foi o momento matricial da imposição planetária da Forma-Mercadoria (MARX, 2013), culminando com as revoluções industriais na Europa, com o regime colonial na América Latina e com a transformação do sistema produtivo feudal no sistema capitalista e sua posterior evolução em diferentes formas ${ }^{5}$. Acentuados desde logo estes pontos, passemos a uma reconstrução breve dos processos históricos, econômicos e sociais que compuseram o mosaico da América Latina.

\section{O pensamento Decolonial e a Sociologia das Ausências e a Sociologia das Emergências}

Aqui, retomemos duas perspectivas que teorizam sobre a construção histórica da América Latina, como um projeto integrado a um sistema mundo moderno colonial (GROSFOGUEL, 2007), o Pensamento Decolonial e a Sociologia das Ausências e a Sociologia das Emergências.

O Pensamento Decolonial surge da necessidade de afirmação política, social, cultural e epistêmica dos povos historicamente silenciados pela modernidade-colonial, assevera que a ciência produzida no norte global se hegemonizou como se fosse a única ciência válida produzida no mundo, além de ressaltarem que a expansão europeia possibilitou a expansão dos seus modelos de ciência (SANTOS, 2010a). Ressaltamos que o Pensamento Decolonial surgiu em várias partes do mundo como resistência e proposição dos povos historicamente silenciados pela modernidade/colonialidade e, como tal, reivindicando formas outras ${ }^{6}$ de pensamento.

\footnotetext{
${ }^{5} \mathrm{Na}$ América Latina várias formas de controle do trabalho coexistiam e coexistem (QUIJANO,2005).

${ }^{6}$ Vale salientar que para o Pensamento Decolonial um "Paradigma Outro" é diferente de "Outro Paradigma" para a compreensão da América Latina. Este seria apenas mais uma variante dentro do mesmo circuito epistemológico, ainda que contra-hegemônico, enquanto aquele representaria uma ruptura epistemológica com a modernidade.
} 
Neste trabalho, utilizamos o Pensamento Decolonial Latino-Americano. Esta vertente surge com as lutas dos Movimentos Sociais ${ }^{7}$ na América Latina, sobretudo Indígena, Negro, Feminista e Campesino. A opção por esta vertente está justificada por possibilitar o deslocamento do lócus de enunciação epistêmica para os povos subalternizados, que torna possível uma visão não europeia do contexto latino-americano, dentro do qual está a trajetória histórica das lutas sociais travadas pelos povos colonizados.

Neste cenário, o Pensamento Decolonial compreende os povos colonizados, dentre eles os povos campesinos, como Lócus de Enunciação Diferenciais (MIGNOLO, 2005) que produzem formas políticas, sociais, epistêmicas e educacionais outras.

Por outro lado (inclusive do oceano atlântico), mas na mesma linha se contra o pensamento sociológico de Santos (2010a; 2010b; 2010c), cuja contribuição ao debate sobre pós-modernidade, colonialismo e ciência moderna é conhecido no mundo todo. Aqui circulamos, em específico, a Crítica da Razão Indolente, sua superação por uma Razão Cosmopolita, através da Sociologia das Ausências e a Sociologia das Emergências.

Estas sociologias criticam a Razão Indolente que fundamentou os conhecimentos científicos e filosóficos produzidos na modernidade-colonial, tendo como contextos hegemônicos o Capitalismo, o Liberalismo, as revoluções industriais, o Imperialismo e o Colonialismo (SANTOS, 2010c).

A Sociologia das Ausências e a Sociologia das Emergências asseveram que o poder social da ciência moderna assenta no controle das concepções de tempo e de temporalidade (SANTOS, 2010a). Neste sentido, questionam a racionalidade ocidental hegemônica, cuja característica mais fundamental é, por um lado, contrair o presente e, por outro, expandir indefinidamente o futuro. A razão que fundamenta tais operações temporais é a razão indolente (SANTOS, 2010a), que é composta da razão impotente, razão arrogante, razão metonímica e razão proléptica.

Nos limites desse texto não será possível desdobar a reflexão sobre a razão impotente, arrogante, metonímica e proléptica. É, no entanto, necessário que compreendamos que as razões metonímica e proléptica são mais amplas e fundamentam as demais. A razão metonímica contrai as experiências do presente, baseando-se em uma ideia de totalidade que obriga à participação em uma identidade comum ${ }^{8}$ e a razão proléptica expande indefinidamente as

\footnotetext{
7 As lutas destes Movimentos Sociais têm se articulado com formas muito distintas das formas privilegiadas pelas teorias críticas: partido e sindicato. Estas manifestações sociais provêm não apenas dos centros industriais e nem utilizam tão somente as línguas coloniais. Pelo contrário, privilegiam os lugares periféricos dos Estados-nação, utilizam línguas nativas e privilegiam a manifestação das diferentes ancestralidades (SANTOS, 2010b).

${ }^{8}$ Concepção de totalidade esta que não compreendem estar relacionada com a totalidade dialética de Marx, ainda que a crítica ao marxismo seja uma tônica da teoria de Boaventura de Sousa Santos.
} 
promessas do futuro ${ }^{9}$, fazendo-as se confundirem com o conceito moderno de progresso, sempre infinito, igual, dogmático e sempre em adiamento.

Deste modo, a Sociologia das Ausências se propõe a aumentar 0 espectro de experiências válidas do presente, apresentando as monoculturas que construíram o abismo entre sociedades metropolitanas e coloniais e as ecologias de superação destas monoculturas modernas. Neste sentido, compreendem que tudo aquilo que não existe, é na verdade ativamente declarado em uma operação colonial como inexistente (SANTOS, 2010a).

Assim, temos a monocultura do saber e do rigor do saber, que adota como referência para as produções científicas e estéticas a epistemologia europeia dominante. A não existência dos povos colonizados, neste contexto, significa a ignorância de não pertencer ao modelo válido de pensamento ou incultura de não pertencer ao universo da alta cultura europeia. Contraposta a esta monocultura está a ecologia de saberes, que reconhece a pluralidade interna e externa da ciência. A pluralidade interna da ciência anuncia outras epistemologias válidas dentro da ciência moderna e transmoderna. A pluralidade externa da ciência abraça todos os conhecimentos que, não sendo científicos, possuem também significado profundo na tradição e cotidiano de muitas culturas (SANTOS, 2010a).

A monocultura da classificação social consiste na distribuição de populações por categorias que naturalizam as hierarquias instituídas, como de raça e de gênero. A não-existência é construída pela inferioridade natural e insuperável, cabendo aos povos subjugados reproduzir a sua inferioridade adjetivada de negra, indígena e feminina (SANTOS, 2010a). Contraposta a esta monocultura está a ecologia de reconhecimentos que parte do princípio que determinados sujeitos coloniais estiveram relegados da condição de humanidade e de reconhecimento mínimo e que, portanto, seus saberes e experiências necessitam se reconhecidas antes mesmo de serem validados.

Na monocultura das temporalidades (SANTOS, 2010a) a história evolui em etapas e progride linearmente em direção ao futuro localizado na Europa. A não existência dos sujeitos se produz sob a forma de atraso em relação ao progresso moderno e seus desenvolvimentos temporais. A ecologia das temporalidades combate esta monocultura, partindo da base de que o tempo e as concepções de temporalidade são divergentes de acordo com as experiências sociais que as originam, superando a perspectiva linear pela circular, glacial, do eterno retorno, dentre outras (SANTOS, 2010a).

A monocultura da escala dominante ou monocultura do universal e do global se refere à capacidade colonial das entidades que se hegemonizaram se declararem universais e globais e designarem as entidades rivais e não

\footnotetext{
9 Aqui, Santos (2010a) aloca a teoria marxista, em uma leitura controversa sobre a suposta inevitabilidade das consequências teóricas, econômicas e políticas que que esta teoria acarretaria.
} 
hegemônicas como particulares e locais. Os acontecimentos que dizem respeito aos povos subalternizados são considerados locais. Assim, a não existência dos povos originários se dá por estes serem residuais diante da Escala Global hegemônica. A monocultura da escala dominante é contraposta pela monocultura trans-escalas, que parte de duas premissas básicas. A primeira é a negação de qualquer regime de construção de alternativas universais, sejam elas, de justiça social, direitos humanos, democracia, solidariedade, dentre outras. A segunda é a da impossibilidade é a de reconhecimento da globalização hegemônica como única porta de possibilidade planetária, uma vez que na concepção de Santos (2010a), toda globalização é, em alguma medida, uma particularidade que se torna hegemônica.

Por fim, a monocultura da produtividade capitalista institui a produção e os critérios da produtividade capitalista como única possibilidade válida e moderna de produção. A inexistência imposta ao mundo colonial é aqui relacionada com a improdutividade. A ecologia de produtividades, de modo contrário, pressupõe o reconhecimento e valorização de inúmeros outros universos produtivos, como a economia solidária, as diferentes formas de produção cooperada e demais experiências produtivas geradas a partir dos diferentes Lócus de Enunciação (SANTOS, 2010a).

Ainda nesta trilha, a Sociologia das Emergências aponta para um contexto de crise das explicações filosóficas ocidentais para colocar em questão seus conceitos dominantes, que são tudo e nada. Estes conceitos reiteram a vocação dicotômica que perpassa a racionalidade filosófica moderna aspirante à universalidade. O conceito de tudo está contido na latência, ou seja, na chance de ser o resultado alcançado (Tudo) ou a frustração (Nada). Cabe ressaltar que os conceitos de Tudo e Nada obedecem à concepção de totalidade moderna, de modo que Tudo (sucesso) ou Nada (fracasso) são sempre pensados entre as epistemologias eurocêntricas.

Segundo Block (1995 apud SANTOS, 2010a), o conceito de possível é o menos privilegiado da filosofia ocidental, sendo justamente neste conceito que estão contidas as experiências sociais do mundo, entre elas as experiências dos povos colonizados, se renovando constantemente.

Em contestação ao privilégio destes conceitos (tudo e nada) pela razão eurocêntrica, a Sociologia das Emergências prioriza os conceitos de Não e Ainda-Não. O conceito de Não significa a falta de alguma coisa e, diante desta falta, o desejo de supri-la. Na medida em que dizemos Não à determinada coisa, estamos também dizendo sim à outra coisa. Desse modo, o conceito de Não se distingue do conceito de Nada ao declarar que a negação a algo nunca é uma negação absoluta caracterizada como Nada, mas sim uma seleção do que aceitar ou recusar. 
O conceito de Ainda-Não, em contraponto com o conceito de Tudo, representa o que ainda não existe concretamente, mas existe como uma tendência. Trata-se de um movimento que pode possibilitar a manifestação de algo, contraindo o futuro para que sua possibilidade de acontecer se torne cada vez mais presente. Uma ruptura com a concepção de futuro validada no pensamento moderno ocidental.

O futuro é aqui concebido não como determinado, mas como indeterminado e pensado não no vácuo, mas nas possibilidades de futuro que, ao serem contraídas, se tornam presentes e aptas a construírem a relação próxima entre presente e futuro.

Ressaltamos a contribuição que as duas correntes teóricas aqui elucidadas oferecem ao debate sobre os processos de colonização e de sedimentação histórica da América Latina. É na própria história de construção do sistema mundo moderno colonial e nos processos de dominação vivenciados neste território, que veremos corporificadas estas contribuições a narrarem a história da modernidade nos mares do Sul.

\section{A produção e reprodução do mundo moderno colonial}

É necessário que partamos de uma tese, cuja pertinência pode ser averiguada na própria história; a de que nas diferentes idades da produção material, a força sempre se impôs como agente capataz que, no limite, visa a garantir os interesses de acumulação e manutenção da ordem material e cultural (MARX, 2007).

Esta tese pode ser verificada nos diferentes cenários históricos que marcaram a produção e reprodução material da vida que havia ascendido das comunidades tradicionais, sem os elementos nucleares do desenvolvimento da agricultura e da pecuária, da propriedade privada e da consequente possibilidade produção de excedente que torna possível a exploração do ser humano sobre o ser humano; passando pelos modos de produção asiático, escravista e feudal, até chegarem ao modo de produção capitalista com a hegemonia da sociedade burguesa (MARX, 2007; 2013).

Toda esta história é, no entanto, tratada como uma história auto referenciada na Europa, sobretudo eclipsando a importância histórica atribuída à construção do regime colonial durante o longo processo de estagnação do desenvolvimento das forças produtivas entre o feudalismo e o capitalismo.

Como dito, o Pachakuti foi decisivo para a vida mundial e representou a colonização dos territórios Abya Yala, no momento em que a Europa não se pensava moderna e no momento em que o estado das forças produtivas ainda não tinha conduzido ao sistema capitalista. Mais do que um faro análogo, 
veremos que o Pachakuti foi fundamental na história da modernidade e do capitalismo.

O Pensamento Decolonial nos permite compreender o processo de construção das duas primeiras identidades históricas da Modernidade: América e Europa (QUIJANO, 2005). As chamadas grandes navegações, empreendidas sobretudo por Portugal e Espanha no século XVI, marcaram o estabelecimento dos primeiros contatos entre os povos que se autodenominaram europeus com os povos nativos dos territórios Tawantisunyu, Anáhuac Abya Yala. ${ }^{10}$

Desta feita, os contatos entre povos nativos e povos invasores ocorreram sob a lógica do Colonialismo, como modelo de dominação, econômica política, social, epistêmica e educacional entre metrópoles (povos colonizadores) e colônias (povos colonizados). Ressaltamos que as colônias foram de povoamento, quando as relações entre metrópole e colônia aconteciam predominantemente pela ocupação territorial (por exemplo, as colônias norte-americanas), ou de assentamento profundo (como as colônias latino-americanas, nas quais a dominação colonial foi exercida com a dependência político-territorial das colônias em relação às metrópoles) ${ }^{11}$. 0 Colonialismo denota uma relação de dependência geográfica que pode ser situada historicamente em diferentes lugares, sendo alimentado por uma lógica interna denominada de Colonialidade (MIGNOLO, 2011).

Baseado na exploração das colônias de assentamento profundo, o Colonialismo ibérico ${ }^{12}$ se estabeleceu através do processo de Colonização, sustentado na lógica da Colonialidade, que, segundo Quijano (2005), ocorreu através de quatro instâncias básicas: a) desintegração dos padrões de poder e de civilização; b) extermínio físico; c) eliminação deliberada de dirigentes, intelectuais e produtores dos patrimônios nativos e d) repressão material e subjetiva aos sobreviventes.

Desta forma as populações nativas (povos indígenas) e traficadas (povos negros) foram tratadas como descartáveis em função do lucro crescente das Coroas Portuguesa e Espanhola. O Colonialismo alicerçou as bases para a consolidação do Capitalismo nos territórios Abya Yala. O outro inferiorizado foi teorizado através da categoria mental e social da Raça, num processo de Racialização. A Racialização foi responsável pela alocação dos povos colonizados em uma hierarquia social na qual os povos europeus, autodenominados brancos, ocupam o lugar de superioridade em relação aos povos colonizados, denominados indígenas e negros.

${ }^{10}$ Tawantinsuyu, Anáhuac e Abya Yala correspondem respectivamente aos territórios Incas, Astecas e região do Panamá (MIGNOLO, 2007).

11 São exemplos de colônias de assentamento profundo as colônias: brasileira, argentina, chilena, entre outras.

12 O Colonialismo lbérico se refere aos modelos de dominação colonial impostos por países que pertenciam à Península Ibérica, especificamente Espanha e Portugal. 
Baseados nesta categoria mental e social, os colonizadores criaram novas identidades raciais com a finalidade de homogeneizar a complexidade existencial dos diferentes povos nativos. Assim, foi possível fundamentar o enquadramento dos diferentes povos nativos na denominação de índios, assim como enquadrar na denominação de negros os diferentes povos traficados do continente africano para servir aos interesses coloniais (QUIJANO, 2005).

Subjacente a estas hierarquias raciais está a Monocultura da Classificação Social (SANTOS, 2010a), que consiste na distribuição de populações por categorias que naturalizam as hierarquias instituídas. A Raça, neste sentido, vincula a explicação das assimetrias sociais para uma suposta natureza inferior das populações subalternizadas. Neste tipo de monocultura são latentes as dominações de Raça e de Gênero, que justificam a missão salvadora das populações classificadas como superiores, notadamente sujeitos da Raça branca e de Gênero masculino. Neste contexto, a não-existência é construída pela inferioridade natural e insuperável, cabendo aos povos subjugados reproduzir a sua inferioridade adjetivada de negra, indígena e feminina (SANTOS, 2010a).

Esta Monocultura da Classificação Social, cujo produto fundamental na Abya Yala foi a categoria mental e social da Raça, justificou a divisão racial do trabalho nos territórios colonizados, de acordo com a superioridade branca e as inferioridades indígena e negra. A estas novas identidades foram atribuídas respectivamente as condições de trabalho assalariado, servidão e escravidão. Estas formas de controle do trabalho se somariam à pequena produção mercantil independente, reciprocidade e capital em uma configuração de formas de articulação do trabalho que coexistiram de modo inédito na história das civilizações ${ }^{13}$ (QUIJANO, 2005). A Sociologia das Ausências propõe, no enfrentamento à monocultura da classificação social, a ecologia de reconhecimentos. A Sociologia das Ausências, e especificamente a Ecologia de Reconhecimentos, "se confronta com a colonialidade, procurando uma nova articulação entre o princípio da igualdade e o princípio da diferença" (SANTOS, 2010a, p. 110).

A ecologia dos reconhecimentos se confronta com a lógica da classificação social, reconhecendo que a desqualificação dos saberes ocorre paralelamente com a desqualificação dos sujeitos que os produzem. Em face disto, busca superar "a Colonialidade do Poder moderno que consiste em identificar diferença como desigualdade, e ao mesmo tempo se arroga dizer quem é igual e diferente" (SANTOS, 2010a, p. 110). Neste sentido, a diferença abarcada pela ecologia de reconhecimentos foi pensada como combate às hierarquias de marcadores biopolíticos, relações entre territórios, lutas étnicas,

${ }^{13}$ Estas formas de controle do trabalho se reforçaram mutuamente nos territórios colonizados, uma vez que dizem respeito aos papéis sociais a serem ocupados por diferentes populações. Esta ideia se contrapõe à visão dual, linear e unidirecional do pensamento moderno (QUIJANO, 2005). 
feministas, de identidade sexual, indígenas, negras, camponesas, dentre tantas outras. Dentre estas lutas destacam-se na América Latina as lutas dos Movimentos Indígena, Negro e Feminista, enfatizando a diversidade de sujeitos e de lutas sociais que se confrontam com o modelo capitalista global neoliberal.

A articulação de formas de controle do trabalho das populações racializadas foi consolidada em função de um "único sistema conjunto de produção de mercadorias para o mercado mundial" (QUIJANO, 2005, p. 20), que tinha no capital o eixo articulador do novo sistema de dominação. Assim, a exploração colonial alicerçou o capitalismo nas terras americanas pela exploração de mão de obra negra e indígena. Assim, foram estabelecidas as condições materiais para a consolidação do sistema capitalista, passando por uma etapa de acumulação primitiva, de subalternização social baseada em naturalização de hierarquias nos territórios invadidos.

A imposição do modo de produção capitalista esteve baseada na Monocultura dos Critérios de Produtividade Capitalista (SANTOS, 2010a). De acordo com Santos (2010a, p. 104), "segundo esta lógica, a não-existência é produzida sobre a forma do improdutivo que, aplicado à natureza, é esterilidade e, aplicada ao trabalho, é preguiça ou desqualificação profissional".

A atual lógica neoliberal se iniciou via racialização e significou na modernidade a predominância do capitalismo, no qual os sujeitos racializados ocupam as posições de inferioridade em relação aos postos de trabalho e consequentemente em relação ao acúmulo de riquezas e controle dos meios de produção capitalista. A ampliação de reconhecimentos de diferentes sujeitos caminha para a afirmação de outras formas de produtividades para além do modelo capitalista de produção, baseando-se em uma ecologia das produtividades.

$\mathrm{Na}$ ecologia de produtividades, as relações sociais estabelecidas entre comunidades e economia extrapolam a lógica de produção hegemônica, de modo que se constroem nos diferentes lócus territoriais de acordo com as suas especificidades culturais. Cabe ressaltar também que a concepção de economia se amplia para vincular as concepções de participação democrática, solidariedade transnacional, equidade social, racial e cultural, além de sustentabilidade ambiental.

São expressões de formas de produção também válidas as organizações econômicas populares, as cooperativas operárias, empresas autogeridas, economia solidária, entre outras (SANTOS, 2010a). Consideramos como importante iniciativa de transgressão à racionalidade econômica e a forma de compreender a importância dos sistemas vivos, a perspectiva agroecológica, que se caracteriza como "um conjunto de conhecimentos sistematizados, baseados em técnicas e saberes tradicionais (de povos originários e camponeses)" (GUHUR; TONÁ, 2012, p. 57). Trata-se de uma concepção ampla de produtividade, que extrapola a compreensão abissal da 
modernidade capitalista, mas que necessita, para se vincular a uma transformação estrutural, estar ligada a um sujeito político revolucionário.

Ressaltamos que a transformação do projeto local europeu em desenho global (MIGNOLO, 2011) impôs não apenas os critérios da validação das experiências sociais, senão a gramática temporal a ser universalmente aceita para a leitura da história. O pensamento eurocêntrico concebe a Modernidade como uma ruptura com a Idade Média; ruptura esta que acontece não apenas em relação aos modos de produção de conhecimentos, mas também à consolidação da ideia de temporalidade histórica linear. Esta leitura histórica atribui a condição de pré-modernidade às experiências sociais que não se situassem no contexto europeu (SANTOS, 2010a), produzindo a não existência dos povos colonizados sob os rótulos de atrasados. Os povos colonizados são considerados anteriores e, portanto, primitivos, pré-modernos. Desta forma, o Eurocentrismo estabeleceu a Monocultura das Temporalidades (SANTOS, 2010a) segundo a qual a história evolui em etapas e progride linearmente em direção ao futuro localizado na Europa. Este futuro, longe do que é declarado na "história oficial', tem como vetor metabólico a América latina, que é a primeira entidade geo-histórica criada na modernidade. Antes da Europa moderna, existiu a América colonial, sem a qual o curso da história seria distinto.

A transgressão à ideia de modernidade pelas sociedades coloniais foi teorizada por Dussel (1994), como Transmodernidade. A transmodernidade é ressaltada por Dussel (1994, p. 22) quando afirma: "no negamos entonces la razón, sino la irracionalidad de la violencia del mito moderno; no negamos la razón, sino la irracionalidad postmoderna; afirmamos la "razón del Otro" hacia una mundialidad Trans-moderna".

A compreensão transmoderna dos territórios colonizados é fortalecida pela ecologia de temporalidades que se opõe à monocultura do tempo linear. Nesta forma de ecologia, o tempo linear instituído na modernidade como estatuto de medição temporal absoluto se converte em apenas mais uma entre muitas concepções de tempo e co-influências históricas entre diferentes mundos no modo de contar o tempo e a história humana. Há, neste sentido, outras concepções de tempo, como por exemplo, o tempo circular, cíclico, glacial e a doutrina do eterno retorno (SANTOS, 2010a). Cada uma destas formas de compreender e se relacionar com as representações de tempo estão localizadas em diferentes territórios culturais. Estes territórios se relacionam de formas distintas com passado, presente e futuro, fazendo com que as linguagens culturais, sejam fundamentalmente linguagens temporais (SANTOS, 2010a).

Será necessário dizer ainda que a imposição do modelo eurocentrado de razão se consolidou como monocultura do saber e do rigor do saber (santos, 2010a), que adota como referência para as produções científicas e estéticas a 
epistemologia europeia dominante. A não existência dos povos colonizados, neste contexto, significa a ignorância de não pertencer ao modelo válido de pensamento ou incultura de não pertencer ao universo da alta cultura europeia.

O deslocamento geo-corpo-político do conhecimento hegemônico se fortalece mediante uma ecologia de saberes que se orienta pela busca de outros saberes e outros critérios de saberes. Segundo Santos (2010a), todas as formas de conhecimento comportam em si formas de ignorância, de maneira que a ciência moderna conhece tanto quanto desconhece

O conhecimento valorizado na modernidade ocidental está relacionado ao capitalismo, regulado pelo mercado, a partir de uma racionalidade cognitivoinstrumental ${ }^{14}$. Assim a forma de ignorância que passa a gerar mais repercussões inferiorizantes é a ignorância em relação ao capitalismo. O contraponto à ideia de monocultura do saber e do rigor do saber é encontrada no conceito de ecologia de saberes, que provoca um amplo debate sobre a importância da valorização da pluralidade de conhecimentos em dois sentidos, o interno e o externo.

A pluralidade interna da ciência se refere às diferentes teorias e paradigmas que se constroem na tentativa de explicação/transformação do mundo, considerando a necessidade de nos interrogarmos sobre a relevância epistemológica, metodológica e política desta pluralidade considerada científica. Neste contexto, as Epistemologias do Sul reivindicam o direito de se construírem sob termos outros de legitimidade acadêmica e social. Para além do debate científico, é importante considerar que o conhecimento se constrói pela tessitura entre diferentes formas de saber, que extrapolam o científico. A respeito disso advoga a pluralidade externa da ciência.

Por sua vez, a pluralidade externa da ciência se refere ao conjunto de epistemologias que não fazem parte do universo de compreensões declaradas científicas, questionando o monopólio das explicações científicas para a realidade. Busca-se, neste sentido, estabelecer conexões solidárias e transformadoras entre a ciência e as outras formas de conhecimento. Diante desta prerrogativa cumpre refletir sobre as epistemologias em dois sentidos

O primeiro sentido se refere à problematização do que é e não é científico, haja vista os sujeitos, os objetos de estudo e as epistemologias que estiveram fora deste reconhecimento na modernidade/colonialidade e que, por transgredirem o científico hegemônico, são considerados não científicos. 0 segundo sentido diz respeito à compreensão de que a ciência não é a única forma de intervenção no mundo, e em determinados contextos, não necessariamente é a melhor (SANTOS, 2010a). Assim, abrem-se

\footnotetext{
${ }^{14}$ Segundo Santos (2010d), a modernidade é constituída pelos pilares da Regulação, composta pelo Estado, pelo Mercado e pela Comunidade, e pelo pilar da Emancipação, com as racionalidades moral-prática, correspondente ao Estado, estético-expressiva, correspondente à Comunidade, e cognitivo instrumental, correspondente ao Mercado.
} 
possibilidades de afirmações para razões sensíveis (MAFFESOLI, 2008), gnoses (MIGNOLO, 2011) e a Racionalidade Estético-expressiva (SANTOS, 2010a).

Pensar em modelos outros de sociedade que consideram as interrelações entre as dimensões econômicas, culturais, políticas e educacionais requer a autonomia epistêmica proveniente das zonas coloniais com suas diferentes geo-políticas e corpo-políticas do conhecimento. Os lugares coloniais se constituem como lócus epistêmico, social e político diferencial em relação ao projeto moderno-colonial. Neste sentido, desobedece epistemologicamente a regulação moderna.

Mediante a Desobediência Epistêmica (MIGNOLO, 2008) se estabelecem debates epistemológicos que extrapolam as regras nas quais cabem os conhecimentos e as epistemologias modernas. Desobedecer, nesse sentido, significa alterar os termos dos diálogos epistêmicos a fim de não permanecer "no domínio da oposição interna aos conceitos modernos e eurocentrados, enraizados nas categorias de conceitos gregos e latinos e nas experiências e subjetividades formadas dessas bases, tanto teológicas quanto seculares" (MIGNOLO, 2008, p. 288 e 289).

Cabe ressaltar que os povos colonizados não se mantiveram passivos diante da dominação imperial, já que os povos nativos, inventados como índios, e os povos traficados do continente africano, inventados como negros, travaram diferentes lutas de resistência ao poder colonial. Os povos indígenas, ao esbarrarem na impossibilidade de resistência baseada na luta armada, resistiram culturalmente preservando ao máximo seus rituais, hábitos, linguagens, desenvolvendo estratégias de negociações possíveis com o poder colonial. Também o suicídio foi utilizado como forma de resistência, uma vez que em algumas cosmologias indígenas a dimensão espiritual pós-morte é uma continuidade divina da existência terrena.

Os povos negros resistiram através dos motins de enfrentamento aos feitores, na mescla da religiosidade que buscava manter vivos elementos das espiritualidades africanas e na construção de bandeiras de luta que afirmassem seu estatuto de humanidade e dignidade. Desta forma, as culturas colonizadas se constituíram na tensão com os povos colonizadores, afirmando atitudes decoloniais (MIGNOLO, 2007), aqui compreendidas segundo a lógica da decolonialidade. Walsh (2008, p. 12) compreende a decolonialidade como

un trabajo que procura a desafiar y derribar las estructuras sociales, políticas y epistémicas de la colonialidad - estructuras hasta ahora permanentes - que mantienen patrones de poder enraizados en la racialización, en el conocimiento eurocéntrico y en la inferiorización de algunos seres como menos humanos. Es a eso a lo que me refiero cuando hablo de la decolonialidad. 
A decolonialidade desafia o parecer eurocêntrico colonial em função da construção de novas tessituras políticas, sociais e epistêmicas fomentadas nas culturas que sofreram com a ferida colonial. Neste sentido, questionam o processo de desumanização que balizou a exploração material e subjetiva empreendida pelos colonizadores.

A decolonialidade existiu mesmo em um contexto em que as diferentes formas de controle do trabalho foram se reforçando simultaneamente baseadas no padrão de pensamento eurocêntrico e com isso a Europa se auto instituía como civilização moderna, uma vez que atribuía a si a primazia do pensamento cientificamente válido. Segundo Quijano (2005), a modernidade se define principalmente sob o signo da racionalidade científica que distingue o moderno do primitivo.

Esta distinção entre moderno e primitivo (cujo critério legitimador era o eurocentrismo) a ser legitimada em todas as partes do mundo foi constituída em uma relação de monocultura do universal e do global. Compreendemos que o processo de consolidação da hegemonia europeia ocorreu impulsionado por uma aspiração à universalidade e, na medida em que esta localidade europeia firmava sua hegemonia, se apropriava da capacidade de designar-se como global e designar os outros territórios como locais (SANTOS, 2010a).

É inexistente, nesta lógica, quem é local, particular, e, portanto, tendente ao desaparecimento (SANTOS, 2010a), assim como os territórios campesinos, enxergados como realidades indesejáveis passíveis de desaparecimento em virtude do capitalismo industrializado cada vez mais crescente.

A consolidação da modernidade eurocêntrica esteve presente nos processos de independência das colônias de assentamento profundo, uma vez que estas independências foram conquistadas não pelos povos nativos, mas pelos descendentes da burguesia colonial constituída pelas elites crioulas ${ }^{15}$. A independência das colônias de assentamento profundo "fue uma consecuencia de los cambios estructurales de la economia y la política de Europa" (MIGNOLO, 2007, p. 78). Assim, as heranças coloniais, que revigoram a lógica da Colonialidade do Poder (MIGNOLO, 2005), alicerçaram a construção dos primeiros Estados Independentes, fazendo com que a dominação colonial se mostrasse igualmente vigorosa mesmo com o fim do regime colonial. $\mathrm{O}$ que surge neste cenário é uma configuração de Estado Uni-Nacional e UniIdentitário, baseado no padrão de classificação colonial.

A Sociologia das Ausências buscar superar aquilo a que nomeia de lógica do universalismo abstrato e a escala global eurocêntrica que mede as demais localidades do mundo. Esta superação se relaciona com uma ecologia

\footnotetext{
${ }^{15}$ Criolos são pessoas nascidas nos territórios colonizados, cujos pais possuem origem europeia ou africana. Mignolo (2007) ressalta que a condição de criolo é ambígua, uma vez que envolve identidades geoculturais imbricadas socialmente.
} 
trans-escalas, que compreende que a divergência é predominante em relação à convergência e reconvergência do mundo e, por isso, o universalismo é considerado arbitrário pelos povos que compõem o Sul Global.

A ecologia trans-escalas busca superar duas formas de ausência. A primeira é a existência de formas alternativas gerais de justiça social, respeito mútuo, solidariedade, comunidade, harmonia cósmica na natureza e sociedade, espiritualidade, entre outras, que impõem uma aplicação universal. Esta tentativa de universalidade abstrata fracassa na medida em que "no nosso mundo, o universalismo existe apenas como uma pluralidade de aspirações universais, parciais e competitivas, todas elas ancoradas em contextos particulares" (SANTOS, 2010a, p. 112).

A segunda exclusão se refere à ocultação das condições sociais que determinam a globalização hegemônica. Toda globalização é concretamente a hegemonia de uma localização que se torna referência e designa as localizações rivais ou alternativas como locais. O local é aprisionado em uma escala que o impede de alcançar a globalidade, caracterizada como globalização hegemônica que se afirma como condição do universalismo. Neste sentido, torna-se necessário reconhecer movimentos inter-escalares que se oponham à globalização hegemônica, desaprisionando-os da escala local, sem, no entanto, instituí-los como universais, já que não há saber total, nem ignorância total, todo saber tem suas ignorâncias e toda ignorância é ignorância em relação a determinados saberes (SANTOS, 2010a).

As Epistemologias do Sul têm advogado em favor da Pluriversalidade. Na ideia de Pluriversalidade questiona-se não apenas a designação hierárquica de quais comunidades são locais e globais, como também o desejo de transformação universal. Neste sentido, os diferentes lugares epistemológicos produzem suas transformações, cujo curso não pode ser captado universalmente, sob pena de estabelecerem-se novas arbitrariedades, desta vez em nome da emancipação. Mais adiante veremos como esta pretensão de desuniversalização da modernidade em seu sentido hegemônico, ainda que sendo motivadas pelas feridas abertas em toda a América latina, carrega consigo também limitações fundamentais no sentido de combate à lógica expansionista e planetária do capital.

Por fim, a o procedimento da Tradução é apontado por Santos (2010a) como possibilidade, mediante o diálogo, da criação de inteligibilidades recíprocas entre diferentes experiências sociais existentes ou planejadas provenientes de diferentes contextos sociais (SANTOS, 2010a). Tal conceito é pensado em duas dimensões; a tradução de saberes, relacionada a uma hermenêutica diatópica, sujo sentido fundamental remete à necessidade de diálogo entre as culturas, dada a sua incompletude mútua e a tradução de práticas de saberes, que se refere à materialidade que ganham os diferentes saberes nas diferentes lutas sociais em relação a objetivos de ação e formas 
de organização. Aqui a preocupação central é com os agentes sociais que transformam os diferentes saberes de diferentes grupos sociais em materialidade.

A Tradução, seja em saberes ou em práticas de saberes, não é um trabalho apenas cognitivo, e desta forma desconfia profundamente da cientificidade moderna/colonial, fazendo dialogar diferentes histórias, corpos, rosto e modos de vida. Deste modo, para as Epistemologias do Sul, ao considerarmos as diferentes culturas e a sua incompletude, consideramos que o futuro não está construído, senão como um Ainda-Não, um devir, cujas pistas devem ser potencializadas a partir de uma Sociologia das Emergências. Uma das possibilidades de Ainda-Não na América Latina é a Interculturalidade, não apenas como categoria teórica que tematiza determinadas relações entre culturas, senão como projeto de sociedade articulado ao Bem Viver (WALSH, 2008).

\section{“América latina sobreviverá?": um solo ontológico para as Epistemologias do Sul}

América latina sobreviverá? Esta é uma pergunta feita por Aníbal Quijano, um dos interlocutores centrais deste escrito, autor este que problematizava a construção histórica da América Latina. Em terras banhadas pelo mesmo mar, Enrique Dusse ${ }^{16}$ fazia eco a um questionamento mais antigo: existe uma filosofia latino-americana? A resposta afirmativa de Dussel se deu na Filosofia da Libertação, em cujo conteúdo está contida a importante formulação de que os seres humanos criam a comunidade de produção e a comunidade de comunicação como formas fundamentais da reprodução da vida em sociedade (DUSSEL, 1995).

As Epistemologias do Sul, cuja ênfase se encontra na comunidade de comunicação, têm como marca fundamental a visibilidade do território latinoamericano como um território específico e diferenciado, apontam para uma preocupação de ordem gnoseológica, uma vez que privilegiam os processos epistemológicos a serem afirmados pelos diferentes povos em suas práticas de vida e na contestação do cânone hegemônico da ciência. Abre-se, neste sentido, uma disputa pela narrativa histórica e epistemológica da América latina, algo que ataca um flanco fundante da modernidade que é o Eurocentrismo e todas as atrocidades que dele decorrem.

Os movimentos e teorias decoloniais aprofundam uma crítica de muito calor epistemológico com repercussão decisiva na educação e na

\footnotetext{
${ }^{16} \mathrm{~A}$ obra de Enrique Dussel sobre o pensamento marxista é composta dos livros: A produção Teórica de Marx, um comentário aos Grundrisse. As metáforas teológicas de Marx, Em direção a um Marx desconhecido: um comentário aos manuscritos de 61-63 e O último Marx (18631882) e a libertação latino-americana.
} 
subalternização política e pedagógica latino-americana. A grande "ausência" está na falta saturação das determinações ontológicas que alicerçam a própria construção epistemológica dominante e as epistemologias subversivas ao padrão de poder colonial.

Que a razão moderna seja indolente é um problema fundamentalmente epistemológico, da indolência que não lhe permite ir adiante na compreensão de um objeto cognoscível, mas que a razão seja capitalista há um substrato ontológico, cuja motivação de sua própria construção remonta em última instância à reprodução material da vida. Decorre daí outro lugar sobre a reflexão decolonial que transborda o âmbito epistemológico, de modo que os homens são artífices da construção histórica, mas não o podem realizar nas condições que desejam, e sim nas condições que herdam dos processos históricos (MARX, 2007).

Para que exista e sobreviva uma América Latina epistemológica, terá sempre sido necessária à sua existência material. Mais do que isso, a centralidade de sua reprodução material na história como motor fundamental de irradiação de seus campos gnoseológicos. Trata-se de subordinar à ontologia do ser social (LUKÁCS, 2010; MARX, 2007) o campo da preocupação gnoseológica e das Epistemologias do Sul e todas as suas importantes contribuições ao debate crítico na Abya Yala.

Dussel (2001) nos adverte de, ao realizar a crítica e a desconstrução da modernidade em relação as suas narrativas epistemológicas, se proceda também a uma desconstrução de seus fundamentos econômicos e políticos. Em sua Filosofia da Libertação, o autor adverte que se trata fundamentalmente de uma "filosofia da fome", motivada por um sujeito fundante pobre, o que não o impede de compreender as determinações do tornar-se pobre de maneira ampla. É assim que o Filósofo da Libertação incorpora um solo materialista ao diálogo hermenêutico-fenomenológico também presente em sua obra.

Ainda na mesma trilha do filósofo, é preciso evidenciar a ausência da categoria trabalho como fundante do ser social na sociologia decolonial de Santos (2010a), uma vez que produtividade, saber e rigor do saber, tempo, escalas e classificação terminam por serem marcadores que dialogam em um mesmo plano epistemológico. Reconhecendo a importância do alargamento produzido através do olhar da Sociologia das Ausências, será igualmente necessário assinalar esta ausência de substrato ontológico da categoria trabalho, que acentua uma compreensão dispersa das múltiplas determinações históricas produzidas além-mar pelo colonialismo.

Igualmente problemática é a abdicação da emergência de um sujeito político revolucionário que contraponha o capital, em suas tendências totalizantes e globais. O abandono desta dimensão está localizado no diagnóstico do caráter parcial e fragmentado de todo e qualquer conhecimento, que necessita estar em diálogo com outros conhecimentos para produzir um 
relato pluriversal e não universal ${ }^{17}$. Cumpre, no entanto, salientar que, embora as condições de construção de um conhecimento absoluto e acabado não sejam possíveis, isto não significa que determinados conhecimentos não tenham validade e potência interpretativa universal. A tradição marxista exemplifica de maneira simples esta formulação ao preocupar-se com os movimentos que constituem a realidade em seu processo de contradição permanente, sendo, portanto, a compreensão dos seus movimentos (que expressam categorias como modos de operar do próprio ser social) e não da realidade em si em todo seu manancial fenomênico a tarefa fundamental da crítica materialista.

Nesta direção, Mészáros (2011) enfatiza que a lógica do capital é incorrigível e irreformável na sua sede de acumulação sempre crescente e Harvey (2016) problematiza a vocação universal de acumulação infinita assumida pelo capital. Deste modo, as alternativas globais, em descrédito desde a queda do muro de Berlim, são aquelas que comportam em si a transgressão não apenas ao modus operandi do capital, senão da sua sede infinita de reproduzir a forma-mercadoria.

As Epistemologias do Sul, em consonância com as críticas da Escola de Frankfurt sobre a racionalidade instrumental também contribuem para sinalizar as fraquezas da razão moderna, da qual é herdeira, em alguma medida, a tradição marxista. A acumulação infinita é contraposta, nas terras do Sul Global pelo Bem Viver, como projeto civilizatório baseado nos modos de vida dos povos afetados pela colonialidade que permite à racionalidade produtiva "decrescer", questionando a suposta salvaguarda do desenvolvimento exponencial das forças produtivas para a humanidade.

Cumpridos os propósitos deste escrito; de demonstrar a importância de um pensar latino-americano sobre a modernidade capitalista, de estreitar criticamente o vínculo entre modernidade e colonialidade e de oferecer uma contribuição ontológica às Epistemologias do Sul, fica sabido que a Abya Yala segue sendo terra em plena madureza para a construção de outro mundo possível, como diz o movimento zapatista.

\section{REFERÊNCIAS}

DUSSEL, Enrique. 1492 El encubrimiento del otro: hacia el origen del "mito de la modernidad". La Paz: Plural, 1994.

DUSSEL, Enrique. Filosofia da libertação: crítica à ideologia da exclusão. São Paulo: Paulus, 1995.

\footnotetext{
${ }^{17}$ Como dito, o procedimento a ser adotado pela crítica da razão indolente seria o da Tradução de saberes e de práticas de saberes, análogo à categoria de Pensamento Fronteiriço ou pensamento de Fronteira do Pensamento Decolonial.
} 
DUSSEL, Enrique. Europa, modernidad y eurocentrismo, in DUSSEL. Hacia una filosofía política crítica, 2001.

GROSFOGUEL, R. Dilemas dos estudos étnicos norte-americanos: multiculturalismo identitário, colonização disciplinar e epistemologias descoloniais. Revista Cienc. Cult. v.59 n.2 São Paulo abr./jun. 2007.Sociedade Brasileira para o Progresso da Ciência. http://cienciaecultura.bvs.br/pdf/cic/v59n2/a15v59n2.pdf

GUHUR, D. M. P.; TONÁ, N. Agroecologia. In: CALDART, R. S. et al (Org.). Dicionário da Educação do Campo. Rio de Janeiro, São Paulo: Expressão Popular, 2012. p. 57-65.

HARVEY, David. 17 contradições e o fim do capitalismo. 1. ed. São Paulo: Boitempo, 2016.

LESSA, Sergio; TONNET, Ivo. Introdução à filosofia de Marx. 2. ed. São Paulo: Expressão Popular, 2011.

LUKÁCS, Gyorgy. Prolegômenos para uma ontologia do ser social: questões de princípios para uma ontologia hoje tornada presente. São Paulo: Boitempo, 2010.

MAFFESOLI, M. Elogio da razão sensível. 4. ed. Petrópolis, RJ: Vozes, 2008.

MARX, Karl. O Capital: Crítica da economia política. Livro I: O processo de produção do capital. Trad. Rubens Enderle. São Paulo: Boitempo, 2013.

MARX, Karl; Engels, Friedrich A ideologia alemã:crítica da mais recente filosofia alemã em seus representantes Feuerbach, B. Bauere Stirner, e do socialismo alemão em seus diferentes profetas (1845-1846). São Paulo: Boitempo, 2007.

MÉSZÁROS, Istivan. Para além do capital: rumo a uma teoria da transição1. ed. revista. São Paulo: Boitempo, 2011.

MIGNOLO, W. D. Cambiando las éticas y las políticas del conocimiento: la lógica de la colonialidade y la postcolonialidad imperial. Herencias coloniales y teorias postcoloniales. Revista chilena de literatura, Coimbra, 2005.

MIGNOLO, W. D. Desobediência epistêmica: a opção descolonial e o significado de identidade em política. Cadernos de Letras da UFF - Dossiê: Literatura, língua e identidade, Rio de Janeiro n 34, p. 287-324, 2008.

MIGNOLO, W. D. Historias locales/diseños globales: colonialidad, conocimientos subalternos y pensamientos fronterizo. Madrid: Akal, 2011.

MIGNOLO, W. D. La Idea de América Latina: la herida colonial y la opción decolonial. Barcelona: Gedisa, 2007.

QUIJANO, A. Colonialidade do poder. In: LANDER, E. (Org.). A colonialidade do saber: eurocentrismo e ciências sociais. Perspectivas latino-americanas. Buenos Aires: CLACSO, 2005.

SANTOS, B. S. A gramática do tempo para uma nova cultura política. 3. ed. São Paulo: Cortez, 2010a. 
SANTOS, B. S. Descolonizar el saber, reinventar el poder. Montevidéu: Trilce, 2010b.

SANTOS, B. S. Para além do pensamento abissal: das linhas globais a uma ecologia de saberes. In: SANTOS, Boaventura de Sousa; MENESES, M. P. (Orgs.). Epistemologias do Sul. São Paulo: Cortez, 2010c. p. 31-83.

WALSH, C. Interculturalidad, Plurinacionalidad y Decolonialidad: Las Insurgencias Político-Epistémicas de Refundar el Estado. Tabula Rasa. Bogotá, Colombia, n. 9, p. 131-152, jul-dic 2008. 